\title{
IMPACT OF TWO REMINERALIZING AGENTS ON BLEACHED ENAMEL MICROHARDNESS
}

\author{
Tamer M. El-Shehawy* ${ }^{*}$ Abeer Ebraheem ${ }^{* *}$ and Nadia M. Zaghloul ${ }^{* * *}$
}

\begin{abstract}
Objective: To evaluate the influence of fluoride varnish and casein phosphopeptide-amorphous calcium phosphate (CPP-ACP) on bleached enamel microhardness.

Materials and Methods: Thirty human permanent incisors were selected to preparer thirty enamel specimens. All specimens were bleached using $40 \%$ hydrogen peroxide bleaching agent (power whiting YF). The bleached enamel samples were divided into three equal groups $(\mathrm{n}=10)$ according to the used remineralizing agent. Group A was treated by CPP-ACP past (GC Tooth mousse), group B was treated by Fl varnish (Biflourid 10) and group C was stored in artificial saliva. The microhardness was assessed using Vicker test (before bleaching, after bleaching and after application of different remineralizing agents). The data was collected and statistically analyze using two-way ANOVA and post hock LSD test at $(\mathrm{P}<0.05)$.
\end{abstract}

Results: Enamel microhardness has diminished significantly in all groups after bleaching. After application of remineralizing agents, there was a significant increase in microhardness. There was no significant difference between groups $\mathrm{A}$ and $\mathrm{B}$, while there was significant difference between these groups and group $\mathrm{C}$.

Conclusions: Using fluoride, CPP-ACPor artificial saliva improves bleached enamel microhardness.

KEYWORDS: CPP-ACP, fluoride, bleaching, microhardness, remineralization

\section{INTRODUCTION}

Vital tooth bleaching is one of the most effective treatment for discolored teeth. ${ }^{(1-3)}$ Bleaching may be performed professionally at clinic (in-office bleaching), or patients may apply a bleaching gel at home customized tray (home bleaching).(4) In- office bleaching is superior to home bleaching in many ways, including dentist control, soft-tissue protection and guard against material ingestion, less treatment time, immediate results and more patient satisfaction. ${ }^{(5)}$ In-office bleaching utilizes concentrations of up to $40 \%$ hydrogen peroxide (HP). ${ }^{(5,6)}$ There is an argument about the negative

* Lecturer, Department of Operative Dentistry, Faculty of Dentistry, Mansoura University, Mansoura.

** BDS, Faculty of Dentistry, Mansoura University, Mansoura.

*** Professor, Department of Operative Dentistry, Faculty of Dentistry, Mansoura University, Mansoura. 
effect of HP or peroxide containing agents. Some studies have found changes in surface morphology, microhardness deterioration and dental hard-tissue volume loss as a result of bleaching..$^{(3,4,7-10)}$

Enamel fluoridation is recommended after bleaching to get rid of these hazards. ${ }^{(4,11)} \mathrm{A}$ calcium fluoride layer was formed on the enamel surface inhibiting demineralization and improves microhardness. ${ }^{(12,13)} \mathrm{CPP}-\mathrm{ACP}$ is a milk-protein derivative, has been introduced for caries prevention and enamel remineralization. ${ }^{(14)}$ The application of a CPP-ACP complex has been recommended following bleaching and professional tooth cleaning, for white spot prevention/removal in orthodontics and as a topical coating for patients suffering from erosion or caries. ${ }^{(15)}$ However, the effect of CPP$\mathrm{ACP}$ on the microhardness of bleached enamel surfaces is uncertain. Hence, this study was conducted to evaluate the effect of fluoride, CPPACP application and storage in artificial saliva on bleached enamel microhardness.

\section{MATERIALS AND METHODS}

Thirty human permanent maxillary central incisors extracted from diabetic patients scheduled for complete denture construction were collected. After extraction, each tooth was thoroughly washed under tap water to remove any remnants and blood. Tissue appendages and debris were removed from their surfaces using a sharp hand sickle scalar (PrimaDent International, Frank. F Germany). Teeth were disinfected in $0.1 \%$ thymol solution for $48 \mathrm{~h}$. Teeth were examined under a stereomicroscope (SZ-PT; Olympus, Japan) at $30 \mathrm{X}$ magnification to ensure that teeth were free of defects, cracks and caries.

Enamel specimens $(5 \mathrm{~mm} \times 5 \mathrm{~mm})$ were prepared using a coarse diamond disk (Struers, 230 CA, USA). Each specimen was mounted in polyvinyle chloride cylinder of $1.8 \mathrm{~cm}$ diameter and $1 \mathrm{~cm}$ height using self-polymerizing acrylic resin (Acrostone, Egypt) to ease handling. To create standardized flat surface, each enamel specimen was polished individually using a coarse, medium, fine and super fine grit disks (Soflex, 3M ESPE, Minnesota, USA) mounted on low speed hand piece under running water. Specimens were assigned into three equal groups $(n=10)$ according to the type of remineralizing agents.

Vickers' MH of all enamel specimens was measured using a digital microhardness tester (Yukon 1202, Buehler, USA). According to the Vickers' method, a diamond point applied pressure to the surface with a $200 \mathrm{kgf}$ load for $10 \mathrm{sec}$, creating a square-shape indentation. Three indentations were made on the surface of specimen and their averages represent final microhardness of the specimen.

Following this procedure, WHITE smile bleaching gel (GC corporation, Tokyo, Japan) containing $40 \%$ hydrogen peroxide was applied to the specimens 3 times (each time for $10 \mathrm{~min}$ ) according to the manufacturer's instruction. Immediately after completion of bleaching and irrigation of specimens, $\mathrm{MH}$ of all samples was measured. After random allocation of enamel specimens into three groups $(n=10)$, specimens of group A was treated by CPP-ACP paste (GC Tooth mousse; GC corporation Tokyo, Japan), twice a day each time for $5 \mathrm{~min}$ for 15 days. Group B specimens was subjected to fluoride varnish (Bifluoride 10; Voco $\mathrm{GmbH}$, Cuxhaven, Germany) immediately after bleaching treatment and after one week. Specimens of group C were stored in artificial saliva for 15 days.

The artificial saliva used in the present study was prepared at Analytical Chemistry department, Faculty of Pharmacy, Mansoura University. The composition of artificial saliva: Methyl -p-hydroxybenzoate $(2 \mathrm{~g} / \mathrm{L})$, Sodium carboxymethyl cellulose (10 $\mathrm{g} / \mathrm{L}), \mathrm{KCl}(0.625 \mathrm{~g} / \mathrm{L}), \mathrm{MgCl}_{2} \cdot 6 \mathrm{H}_{2} \mathrm{O}(0.059 \mathrm{~g} / \mathrm{L})$, $\mathrm{CaCl}_{2} .2 \mathrm{H}_{2} \mathrm{O}(0.166 \mathrm{~g} / \mathrm{L}), \mathrm{K}_{2} \mathrm{HPO}_{4}(0.804 \mathrm{~g} / \mathrm{L})$ and $\mathrm{KH}_{2} \mathrm{PO}_{4}(0.326 \mathrm{~g} / \mathrm{L})$.The $\mathrm{PH}$ of artificial saliva was adjusted to 7.4 with $\mathrm{KOH}$, artificial saliva was changed daily. Finally, $\mathrm{MH}$ of all specimens was measured. 
Results were statically analyzed using Two-way ANOVA and Post Hoc LSD test at $(P<0.05)$ using SPSS software program (SPSS version 22, IBM, Chicago, IL, USA).

\section{RESULTS}

Means, standard deviations and post hock LSD results of all groups are presented in table-1 and figure-1. It was obvious that there was no significant difference among measurements before bleaching (base line) and the mean values range from $374.86 \pm 14.27$ to $380.02 \pm 12.8 \mathrm{VHN}$. Also, after bleaching there was no significant differences between measurements and mean values ranged from $360.78 \pm 13.78$ to $365.36 \pm 9.27$ VHN. After bleaching, there was highly significant drop in mean of microhardness $(p<0.001)$. After application of different remineralizing agents, there was significant improvement of microhardness $(\mathrm{p}<0.05)$; in case of fluoride $(398.12 \pm 11.79 \mathrm{VHN})$ and in case of CPP$\operatorname{ACP}(398.98 \pm 14.2 \mathrm{VHN})$. Storage in artificial saliva improves microhardness to the base line values $(372.94 \pm 12.9 \mathrm{VHN})$. The results of post hock LSD showed that there was no significant difference between the effect of fouride and CPP-ACP on microhardness of enamel but there was significant difference between them and group immersed in artificial saliva.

TABLE (1) Means \pm standard deviations in VHN and Post Hoc LSD results for all groups.

\begin{tabular}{|c|c|c|c|}
\hline & Baseline & After Bleaching & After Remineralization \\
\hline GC Tooth mousse & $380.02 \pm 12.8^{\mathrm{A}}$ & $365.36 \pm 9.27^{\mathrm{B}}$ & $398.98 \pm 14.2^{\mathrm{Ca}}$ \\
\hline Bifluoride 10 & $375.15 \pm 11.28^{\mathrm{A}}$ & $360.78 \pm 13.78^{\mathrm{B}}$ & $398.12 \pm 11.79^{\mathrm{Ca}}$ \\
\hline Artificial saliva & $374.86 \pm 14.27^{\mathrm{A}}$ & $364.66 \pm 11.7^{\mathrm{B}}$ & $372.94 \pm 12.9^{\mathrm{Ab}}$ \\
\hline
\end{tabular}

The same small superscripted letters denote non-significant difference between groups in same column and similar capital superscripted letters denote non-significant difference in same row.

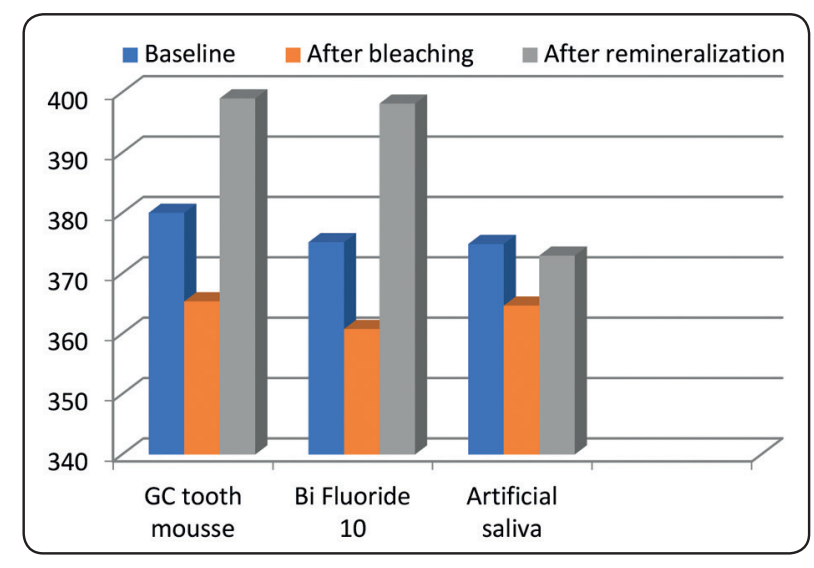

Fig. (1) Abar chart of the microhardness mean values in VHN for all groups.

\section{DISCUSSION}

Bleaching is an easy and conservative method for treating discolored teeth than veneers and laminations. Bleaching is a whitening method that can occur in a solution or on the surface. The color producing materials are organic compounds that possess long conjugated chains of alternating single or double bonds. Such compounds in the conjugated system often include hetero atoms, carbonyl, and phenyl rings and are often referred to as chromophore. Chromophore bleaching may occur through dissolution of one or more of the double bonds in the conjugated chain or through the oxidation of other chemical moieties in the conjugated chains. ${ }^{(16)}$ 
Hydrogen peroxide bleaching can proceed via the perhydroxyl anion or free radicals depending on $\mathrm{pH}$. Because the peroxide diffuses into the tooth, it can react with organic color materials found inside the tooth structure resulting in color reduction. These oxidation reactions can cause alterations in the enamel structure ${ }^{(17)}$ calcium and phosphate mineral loss, ${ }^{(18)}$ and pulpal sensitivity. The results of these studies which are in accordance with the studies done by Al-Salehi et al. ${ }^{(9)}$, Elfallah et al. ${ }^{(19)}$ showed clearly that the application of bleaching gel lowered the microhardness of the enamel and also showed the changes in enamel are directly proportional to concentration of bleaching agent which are in similar to the studies done by Hegedus et al., ${ }^{(20)}$ The results are in contrast with the study of Basting et al. ${ }^{(21)}$

There was a statistically significant increase in mean surface microhardness after storage in artificial saliva. Saliva not only has a cleaning function and improves oral comfort but also has a buffering action due to the inorganic electrolytes contained in it (calcium, phosphourous and fluoride). These inorganic electrolytes are important participants in the remineralization process of dental hard tissues that could improve the microhardness of the bleached enamel. ${ }^{(22)}$

This was in agreement with Nathoo et al. who found that enamel alterations due to the effect of $10 \%$ carbamide peroxide; revert to almost normal within three months. ${ }^{(23)}$ Carbamide peroxide found to decrease enamel microhardness and deteriorate surface morphology. Smidt et al. reported that "the buffering ability and the remineralization potential of saliva could overcome detrimental bleaching effect. When artificial saliva is used to mimic the natural saliva features, the detrimental effect of bleaching was less apparent". (24)

There was a statistically significant increase in mean surface microhardness of group remineralized by (Bifluoride 10). Preventing bleaching agent demineralizing effects is likely due to the ability of sodium fluoride to remineralize hard tooth structure. ${ }^{(25)}$ Fluoride leads the formation of calcium fluoride deposits on tooth surface. ${ }^{(26)}$ these results are in agreement with Kemaloğlu et al., ${ }^{(27)}$ Fukuyama et al. ${ }^{(28)}$ and Borges et al. ${ }^{(29)}$ as they concluded that sodium fluoride induct the formation of fluorapatite or fluorhydroxyapatite. This was in contrast to a study by Araujo et al. that said the use of fluoride varnish did not significantly improve the microhardness of bleached enamel. ${ }^{(30)}$

Casein phosphopeptides are multi phosphorylated from the bovine milk protein casein enzymatic digestion. These peptides stabilize calcium phosphate in solution as amorphous calcium phosphate (ACP), CPP bind to form nanoclusters of ACP in metastable solution, inhibiting their growth to critical size needed for nucleation and phase transformation. CPP-ACP nanoclusters have been shown to locate at the tooth surface. CPP-ACP buffers free calcium and phosphate ion activity by helping to maintain a supersaturating state with regard to tooth enamel which depresses demineralization and stimulate remineralization. ${ }^{(31,32)}$

The results of this study showed that there was a definitive increase in microhardness when compared to the post-bleach microhardness. The addition of ACP components to the salivary system at normal oral $\mathrm{pH}$ and temperature will cause $\mathrm{ACP}$ hydrolysis into apatite within a few minutes, which is approximately 20,000 times faster than normal. (33) In current study, surface MH of teeth increased at the end of the study ,compared to the baseline value, in all three groups after the exposure to the two mineralizing agents as well as artificial saliva. It could be argued that artificial saliva could only have the ability to restore the surface $\mathrm{MH}$ to baseline levels, as normally occurs in the oral environment. The only possible explanation for these results could be that, these findings may be due to that the micro porosities formed by bleaching on the subsurface 
enamel provides susceptible areas for re-deposition of these materials with higher mineral content, similar to that which occurs in arrested caries. Perfect conditions for enamel remineralization in oral cavity are available. After bleaching, calcium and phosphrus exchange is an easy process leading to more mineral absorption replacing those lost by bleaching process. ${ }^{(34)}$ This phenomenon explains why $\mathrm{MH}$ value greater than that of sound enamel.

\section{CONCLUSION}

Using Bifluoride 10 and CPP-ACP are recommended for patients after bleaching treatment as they are able to remineralized damaged enamel surfaces and render these surfaces more resistant to acid attack.

\section{REFERENCES}

1. Papathanasiou A, Bardwell D, Kugel G. A clinical study evaluating a new chairside and take-home whitening system. Compend Contin Educ Dent 2001;22(4):289-94.

2. Donly KJ, Donly AS, Baharloo L, Rojas-Candelas E, Garcia-Godoy F, Zhou X, et al. Tooth whitening in children. Compend Contin Educ Dent 2002;23(1A):22-8.

3. Bistey T, Nagy IP, Simo A, Hegedus C. In vitro FT-IR study of the effects of hydrogen peroxide on superficial tooth enamel. J Dent 2007;35(4):325-30.

4. Lewinstein I, Fuhrer N, Churaru N, Cardash H. Effect of different peroxide bleaching regimens and subsequent fluoridation on the hardness of human enamel and dentin. J Prosthet Dent 2004;92(4):337-42.

5. Luk K, Tam L, Hubert M. Effect of light energy on peroxide tooth bleaching. J Am Dent Assoc 2004;135(2):194-201.

6. Gallagher A, Maggio B, Bowman J, Borden L, Mason S, Felix H. Clinical study to compare two in-office (chairside) whitening systems. J Clin Dent 2002;13(6):219-24.

7. Lewinstein I, Hirschfeld Z, Stabholz A, Rotstein I. Effect of hydrogen peroxide and sodium perborate on the microhardness of human enamel and dentin. J Endod 1994;20(2):61-3.

8. Gultz J, Kaim J, Scherer W, Gupta H. Two in-office bleaching systems: a scanning electron microscope study. Compend Contin Educ Dent 1999;20(10):965-8, 70.
9. Al-Salehi SK, Wood DJ, Hatton PV. The effect of $24 \mathrm{~h}$ nonstop hydrogen peroxide concentration on bovine enamel and dentine mineral content and microhardness. J Dent 2007;35(11):845-50.

10. Sulieman M, Addy M, Macdonald E, Rees JS. A safety study in vitro for the effects of an in-office bleaching system on the integrity of enamel and dentine. J Dent 2004;32(7):581-90.

11. Attin T, Kielbassa AM, Schwanenberg M, Hellwig E. Effect of fluoride treatment on remineralization of bleached enamel. J Oral Rehabil 1997;24(4):282-6.

12. Featherstone JD, Cutress TW, Rodgers BE, Dennison PJ. Remineralization of artificial caries-like lesions in vivo by a self-administered mouthrinse or paste. Caries Res 1982;16(3):235-42.

13. White DJ, Featherstone JD. A longitudinal microhardness analysis of fluoride dentifrice effects on lesion progression in vitro. Caries Res 1987;21(6):502-12.

14. Reynolds EC. Remineralization of enamel subsurface lesions by casein phosphopeptide-stabilized calcium phosphate solutions. J Dent Res 1997;76(9):1587-95.

15. Wegehaupt FJ, Taubock TT, Stillhard A, Schmidlin PR, Attin T. Influence of extra- and intra-oral application of CPP-ACP and fluoride on re-hardening of eroded enamel. Acta Odontol Scand 2012;70(3):177-83.

16. Kihn PW. Vital tooth whitening. Dent Clin North Am 2007;51(2):319-31.

17. Sulieman M, Addy M, Macdonald E, Rees JS. The bleaching depth of a $35 \%$ hydrogen peroxide based inoffice product: a study in vitro. J Dent 2005;33(1):33-40.

18. Grobler SR, Majeed A, Moola MH. Effect of various tooth-whitening products on enamel microhardness. SADJ 2009;64(10):474-9.

19. Elfallah HM, Swain MV. A review of the effect of vital teeth bleaching on the mechanical properties of tooth enamel. N Z Dent J 2013;109(3):87-96.

20. Hegedus C, Bistey T, Flora-Nagy E, Keszthelyi G, Jenei A. An atomic force microscopy study on the effect of bleaching agents on enamel surface. J Dent 1999;27(7):509-15.

21. Basting RT, Rodrigues AL, Jr., Serra MC. The effect of $10 \%$ carbamide peroxide, carbopol and/or glycerin on enamel and dentin microhardness. Oper Dent 2005;30(5):608-16.

22. Shannon IL, Trodahl JN, Starcke EN. Remineralization of enamel by a saliva substitute designed for use by irradiated patients. Cancer 1978;41(5):1746-50. 
23. Nathoo SA, Chmielewski MB, Kirkup RE. Effects of Colgate Platinum Professional Toothwhitening System on microhardness of enamel, dentin, and composite resins. Compend Suppl 1994(17):S627-30.

24. Smidt A WD, Roman I, Gedalia I. Effect of bleaching agent on microhardness and surface morphology of tooth enamel. J Am Dent 1998;11:83-85.

25. Orchardson R, Gillam DG. The efficacy of potassium salts as agents for treating dentin hypersensitivity. J Orofac Pain 2000;14(1):9-19.

26. Cavalli V, Rodrigues LK, Paes-Leme AF, Soares LE, Martin AA, Berger SB, et al. Effects of the addition of fluoride and calcium to low-concentrated carbamide peroxide agents on the enamel surface and subsurface. Photomed Laser Surg 2011;29(5):319-25.

27. Kemaloglu H, Tezel H, Ergucu Z. Does post-bleaching fluoridation affect the further demineralization of bleached enamel? An in vitro study. BMC Oral Health 2014;14:113.

28. Fukuyama M, Kawamoto C, Saikaew P, Matsuda Y, Carvalho RM, Selimovic D, et al. Effect of topical fluoride application on enamel after in-office bleaching, as evaluated using a novel hardness tester and a transverse microradiography method. Eur J Oral Sci 2017;125(6):471-78.

29. Borges AB, Yui KC, D’Avila TC, Takahashi CL, Torres $\mathrm{CR}$, Borges AL. Influence of remineralizing gels on bleached enamel microhardness in different time intervals. Oper Dent 2010;35(2):180-6.

30. Araujo NC, da Costa Soares MU, Nery MM, Sales WS, Gerbi ME. Effect of $\mathrm{pH}$ values of two bleaching gels on enamel microhardness. Gen Dent 2013;61(4):55-8.

31. Reynolds EC. Anticariogenic complexes of amorphous calcium phosphate stabilized by casein phosphopeptides: a review. Spec Care Dentist 1998;18(1):8-16.

32. LeGeros RZ, Silverstone LM, Daculsi G, Kerebel LM. In vitro caries-like lesion formation in F-containing tooth enamel. J Dent Res 1983;62(2):138-44.

33. Cochrane NJ, Reynolds EC. Calcium phosphopeptides -mechanisms of action and evidence for clinical efficacy. Adv Dent Res 2012;24(2):41-7.

34. Justino LM, Tames DR, Demarco FF. In situ and in vitro effects of bleaching with carbamide peroxide on human enamel. Oper Dent 2004;29(2):219-25. 